\title{
Guerra, liderazgos políticos y pueblos de frontera. El ataque militar a la justicia de Maldonado en 18281 $^{1}$
}

\author{
War, political leadership and border towns. The military \\ attack on the Maldonado justice in 1828
}

Santiago Delgado

Universidad de la República, Uruguay

https://orcid.org.0000-0002-6776-5732

DOI: https://doi.org/10.25032/crh.v6i11.9

Recibido: $15 / 10 / 2020$

Aceptado: 6/12/2020

Resumen. El 12 de abril de 1828 las autoridades de justicia de Maldonado fueron sorpresivamente tomadas prisioneras por una partida al mando del coronel Pedro Oroná, jefe interino de las milicias activas del departamento. El episodio, escasamente abordado por la historiografía, se dio en un contexto de conflictos en la Provincia Oriental entre autoridades civiles y militares, ante las dificultades que presentaba la guerra contra el Imperio del Brasil. En el presente trabajo se propone reconstruir el suceso a través del expediente judicial levantado en 1828, incluyendo también relación de correspondencia oficial y privada, memorias y diarios de guerra. Su estudio permitirá dar cuenta de ciertos límites de las jefaturas militares, indagar en las complejas tramas locales en la que se apoyaron, y matizar ciertas nociones sobre el caudillismo en la campaña rioplatense a principios del siglo XIX, fenómeno objeto de revisión en las últimas décadas por la historiografía latinoamericana.

Palabras clave: Guerra; Caudillismo; Milicias; Maldonado; Pueblos

\footnotetext{
1. Una versión anterior del presente trabajo fue presentada en la mesa «Participación social y política», coordinada por Jaime Yaffé y Pablo Ferreira, en el Segundo Congreso de la Asociación Uruguaya de Historiadores realizado en Montevideo el 20, 21 y 22 de junio de 2019. La presente es uno de los resultados del proyecto de investigación, «Pueblos de frontera y fuerzas en armas. El proceso de construcción provincial y estatal en Maldonado. 18201838», financiado por la Comisión Sectorial de Investigación Científica (CSIC) de la Universidad de la República y realizado en el marco del Grupo de investigación CSIC «Crisis revolucionaria y procesos de construcción estatal en el Río de la Plata», coordinado por los profesores Ana Frega y Nicolás Duffau. Agradezco a Darina Martikanova y a los integrantes del Taller «Historiadores: entre expertos y ciudadanos» de la Universidad Autónoma de Madrid por los comentarios realizados durante la presentación de una versión preliminar del texto.
} 
Abstract. On April 12, 1828, the Maldonado justice authorities were surprisingly taken prisoner by a party under the command of colonel Pedro Oroná, acting head of the active militias in the department. The episode, scarcely addressed by historiography, occurred in a context of conflicts in the Oriental Province between civil and military authorities, given the difficulties that the war against the Empire of Brazil presented. In the present work it is proposed to reconstruct the event through the judicial file raised in 1828, also including a list of official and private correspondence, memoirs and war diaries. Its study will allow to account for certain limits of the military headquarters, investigate the complex local plots on which they were based, and clarify certain notions about warlordism in the River Plate campaign at the beginning of the 19th century, a phenomenon that has been reviewed in recent decades by Latin American historiography.

Keywords: War; Warlordism; Militas; Maldonado; Towns

\section{Introducción}

El Departamento de Maldonado fue creado en 1816 en el marco de una organización territorial de la Provincia Oriental. Se ubicaba al sur de río Negro y en la frontera este de la provincia, con la laguna Marín como límite con el Imperio del Brasil. ${ }^{2}$ San Fernando de Maldonado se transformó en su cabecera subordinando a su jurisdicción a las autoridades de las villas de San Carlos, Rocha, Minas y el pueblo de Santa Teresa. En esta decisión pesó su calidad de ciudad con cabildo y puerto menor, condiciones que también ayudaron a construir lazos entre sus notables y diferentes centros de poder en la región platense. 3

Esta organización territorial continuó vigente durante el dominio luso-brasilero de la provincia, nombrada Cisplatina desde 1821. En 1825 el éxito de la expedición militar liderada por Juan Antonio Lavalleja permitió la conformación de un nuevo orden provincial, el cual controló buena parte del territorio y confinó a las autoridades cisplatinas a las ciudades de Montevideo y Colonia del Sacramento. En la villa de la

\footnotetext{
${ }^{2}$ En la actualidad dicho espacio está ocupado por los departamentos de Maldonado, Rocha y Lavalleja, que forman parte de la actual República Oriental del Uruguay.

3 Marcela Ternavasio ha caracterizado a los «notables» como aquellos sectores sociales que ocuparon posiciones de dominio con respecto al resto de sus vecinos, principalmente a través de su participación en el gobierno del Estado en formación (113).
} 
Florida se constituyó una Sala de Representantes que proclamó nulos los vínculos con el Imperio del Brasil y resolvió la unión a las Provincias Unidas del Río de la Plata, lo que derivó luego en la declaración de guerra del emperador Pedro I.

La Sala de Representantes de la denominada nuevamente Provincia Oriental tomó posición en el enfrentamiento en el Congreso Constituyente de las Provincias Unidas de 1824, entre los sectores que proponían una organización unitaria del estado y los que promovían una de carácter federal. Durante sus sesiones se sancionó un conjunto de leyes que cambiaron la organización de la administración y el esquema fiscal de la provincia, inspiradas en las reformas realizadas en la provincia de Buenos Aires entre 1821 y 1824 por su entonces ministro de gobierno Bernardino Rivadavia. El objetivo era instaurar un orden que dejara atrás el estado de movilización de la revolución, centralizara la autoridad y recaudara los recursos necesarios para afrontar los costos de la guerra contra el Imperio del Brasil. El nuevo esquema sufrió la resistencia de los poderes locales y fue una de las causas de su apoyo a la disolución de la Sala de Representantes por parte de Lavalleja a fines de 1827 (Cuadro 2009).

En su calidad de gobernador provisorio, el 6 de diciembre de 1827 Lavalleja decretó un nuevo ordenamiento de la justicia, creando en cada ciudad cabecera los Consejos de Administración de Justicia. Esta institución debía estar integrada de forma anual por un alcalde, un defensor de pobres y un fiscal del crimen, electos por el gobierno a través de listas conformadas según el voto de los vecinos.4 $\mathrm{Al}$ igual que los extintos cabildos, los consejos cumplieron funciones de justicia y velaron por los intereses de su jurisdicción, proponiendo medidas al gobierno de la provincia. Junto a los curas párrocos y a los comandantes militares constituían las principales autoridades del entramado institucional departamental (Delgado, 2017).

El 11 de julio de 1828 el Consejo de Administración de Justicia de Maldonado y el juez de la Cámara de Apelaciones de la Provincia Oriental, Carlos Anaya, fueron atacados por el jefe interino de las milicias del departamento, el coronel Pedro Orona. Ante la negativa del comisionado y los jueces de recibirlo para discutir las acusaciones de las que fue objeto, entre ellas obligar a los vecinos del departamento a firmar

\footnotetext{
4 «Administración de Justicia. Creación de un alcalde, un defensor de pobres y un agente fiscal en cada Departamento, Durazno, 6 de diciembre de 1827», en Armand Ugón, E., et al., Compilación de leyes y decretos, 1825-1834, Tomo I (Montevideo: s.d., 1930): 81.
} 
peticiones a favor del comandante militar del departamento Leonardo Olivera, Orona ordenó a sus oficiales que los arrestaran. 5 La maniobra se habría frustrado por la rápida acción de Anaya, enviado por el gobierno oriental para solucionar las diferencias entre el ayuntamiento y Olivera (que en esos momentos se encontraba fuera del departamento). Según relató al gobierno provincial, se enfrentó a los oficiales manifestando su calidad de comisionado y luego apresó a los demás integrantes de la partida mediante amenazas de sanciones. ${ }^{6}$ Posiblemente también lo favoreció su trayectoria militar, así como sus vínculos con la notabilidad de Maldonado.7 Al día siguiente Anaya se entrevistó con Orona y acordaron una reconciliación, indicada en una proclama que redactó el comisionado y que fue ratificada por los concejales afectados. ${ }^{8}$

El ataque se produjo en un contexto complejo en la región rioplatense, caracterizada por las luchas de facciones y el resurgimiento de movimientos armados (Ayrolo 2008). Los enfrentamientos entre los ejércitos de las Provincias Unidas y el Imperio del Brasil parecían estancarse por las dificultades financieras que generó la prolongación de la guerra, mientras los agentes británicos mediaban para conseguir la

\footnotetext{
5 Preguntado por los motivos del intento de arresto, el alferes ayudante Joaquín Tabares habría declarado que Orona quiso llegar al «estremo de querer prender alos Sores del consejo y al com.o y remitirlos al ejercito». Interrogatorio a Joaquin Tabares, Maldonado, 3 de setiembre de 1828, en Causa contra el Teniente Coronel Pedro Orona, 1828, Archivo General de la Nación (AGNuy), Montevideo, Fondo exArchivo General Administrativo (ex-AGA), Libro 1378, f. 59.

6 Carlos Anaya, Comisionado por el Gobierno, al Gobierno Delegado de la Provincia Oriental, Maldonado, 14 de julio de 1828, en Causa contra el Teniente Coronel Pedro Orona, 1828, AGNuy, Montevideo, ex-AGA, Libro 1378, f. 1.

7 Carlos Anaya nació el 4 de noviembre de 1777 en la villa de San Pedro de la jurisdicción de la gobernación de Buenos Aires. Según José María Fernández Saldaña, a los 20 años pasó a residir en Montevideo donde ejerció como comerciante (Fernández 1945, 62). Probablemente esta actividad le permitió establecer vínculos con los notables de la ciudad de Maldonado, de cuyo cabildo fue nombrado apoderado para negociar los arbitrios para la construcción de un templo en 1824 ante el capitán de la Provincia Cisplatina Federico Lecor (Cabildo. Correspondencia con el ap.do del Cabildo Carlos Anaya. 1824. N. ${ }^{\circ}$ 325, en AGNuy, Montevideo, Archivo Judicial (AJ), Juzgado Letrado Departamental de Maldonado, Caja 23, s.f.). En 1825 fue electo por dicha jurisdicción para integrar la Sala de Representes de la Florida. Formó parte del círculo cercano a Lavalleja y por su calidad de «ciudadano de ilustración y condiciones poco generales en la época» fue designado en 1825 como comisario general de guerra y secretario de gobierno y hacienda entre abril y julio de 1826 (Fernández 1945, 62). Un año después fue designado juez de primera instancia del Departamento de Maldonado, cargo que ejerció hasta su supresión con la reforma de Lavalleja en 1827. Al año siguiente fue nombrado miembro del Tribunal de Apelaciones. Luego de la creación del Estado Oriental ocupó cargos legislativos y en reiteradas ocasiones la presidencia del poder ejecutivo en calidad de presidente del senado. En 1838 redactó sus memorias biográficas donde da su particular versión del ataque, especialmente crítica con la actuación de Orona y Olivera («Memoria autobiográfica de Carlos Anaya», Revista Histórica, 103-105 (Montevideo: Barreiro y Ramos, 1964), 604-776).

8 Proclama de Carlos Anaya a los Habitantes del Departamento de Maldonado, Maldonado, 12 de julio de 1828, en Causa contra el Teniente Coronel Pedro Orona, 1828, AGNuy, Montevideo, ex-AGA, Libro 1378 , f. 17.
} 
paz. Las tropas tropas del ejército republicano sufrían una imparable deserción de sus filas que repercutió en el crecimiento del bandolerismo en la Provincia de Buenos Aires (Di Meglio 2018).

En la Provincia Oriental los enfrentamientos entre las jefaturas militares y los miembros de la disuelta Sala de Representantes se recrudecieron. Al decir de Eduardo De Salterain y Herrera se estaban produciendo un conjunto de disidencias vecinales que enfrentaron a comandantes locales con autoridades civiles, como sucedió en las villas de Soriano y Paysandú (De Salterain y Herrera, 166-180). Más cerca del frente de guerra, Lavalleja, jefe del ejército oriental, disputaba el poder de la Provincia Oriental con Fructuoso Rivera, líder militar independentista que se había integrado al gobierno luso-brasilero hasta 1825, cuando se sumó a la sublevación. ${ }^{9}$ En este contexto el gobierno provincial desconoció el pacto logrado por Anaya y ordenó un juicio civil a los implicados, sin tener en cuenta su fuero militar.

El episodio ha sido escasamente abordado por la historiografía uruguaya y la literatura sobre la región de Maldonado, a pesar de la repercusión que tuvo en su momento. Por ello se propone el análisis del expediente judicial levantado por el juez Juan José Alsina durante el juicio sumario a Orona y sus oficiales, custodiado en el Archivo General de la Nación de Uruguay. Teniendo en cuenta las complejidades que presenta en este tipo de testimonios, donde la voz de los implicados está mediada por la autoridad judicial, así como atravesada por las diferentes estrategias de los acusados para evitar su condena (Farge 1991, 63), se ha enriquecido el análisis con documentación edita e inédita, como relación de correspondencia oficial y privada, memorias, diarios de guerra y repertorios biográficos de autores locales. Su estudio se hizo desde un enfoque que de cuenta de la relación entre la dimensión local y regional del fenómeno estudiado, en una provincia/estado en construcción, que compartía con las formaciones limítrofes un mismo paisaje agrario y con las particularidades de una zona de fronteras como lo era el departamento de Maldonado en la primera mitad del siglo XIX. ${ }^{10}$

\footnotetext{
9 Sobre los diferentes proyectos en disputa entre el dominio luso-brasilero y la constitución del Estado Oriental en 1828, cfr. Frega 2009, en especial los capítulos 3 y 4.

${ }^{10}$ Sobre el estudio del período independentista desde un enfoque regional, cfr. Frega 2009. Sobre las particularidades de la frontera entre Uruguay y Brasil cfr. Susana Bleil y Fabricio Prado 1999. En su investigación sobre desarrollo de la estructura económica de Rio Grande del Sur, Helen Osório destacó las relaciones e intereses en común con sus vecinos de la Banda Oriental y Buenos Aires, entendiendo
} 
El trabajo se enmarca en la renovación historiográfica sobre la experiencia militar durante la crisis del orden colonial y las luchas por las guerras por la independencia en el Río de la Plata. La precursora obra de Tulio Halperin Donghi Revolución y guerra destacó el papel de las autoridades militares en la formación de una clase dirigente durante este período, desde un enfoque que superó la preconfiguración de los estados nacionales (Halperin Donghi 2005 [1972]). En este marco distintos autores han profundizado en la organización de los cuerpos armados, los intentos y fracasos en su reforma, su heterogénea composición social, así como las formas de hacer la guerra durante la crisis del orden colonial y la construcción de los estados independientes (Marchena Fernández 1992; Fradkin, 2005 y 2012; Frega 2014). Asimismo, desde nuevos enfoques se ha analizado formas de acción colectivas, como las «montoneras», a través del estudio de expedientes judiciales y otras fuentes, restituyendo su carácter político y superando así el rol pasivo que la historiografía tradicional asignó a los sectores subalternos (De la Fuente, 1998; Fradkin 2006).

En paralelo a esta renovación se ha discutido la construcción de liderazgos en la campaña rioplatense, en especial el rol de los caudillos. A partir del estudio de la trayectoria del jefe militar riojano Juan Facundo Quiroga, Noemí Goldman cuestionó el tradicional abordaje de estos actores desde de la dicotomía doctores/caudillos (relacionada con la oposición civilización/barbarie), ya que no siempre establecieron relaciones políticas de sometimiento con sus bases y en reiteradas ocasiones reivindicaron el respeto a las leyes y el orden institucional (1993). Por su parte José Carlos Chiaramonte ha señalado que el concepto de caudillo se debe analizar en el marco de la vigencia de la «antigua constitución», conjunto de costumbres y normas que aludían a la tradición legal hispana, además de tener en cuenta aspectos como su formación intelectual o el de quienes los acompañaban (2010).

Para el caso de la Provincia Oriental Lucía Sala, Julio Rodríguez y Nelson de la Torre han destacado el carácter radical del artiguismo a partir de su propuesta de proteger la posesión de tierras de los sectores que apoyaron la revolución (1969). Posteriormente, José Pedro Barrán cuestionó el carácter subordinado de los sectores populares que predominaba en la historiografía uruguaya y definió al líder disputas fronterizas (Osório 2007). Sobre la caracterización de territorios como «zona-fronteras cfr. Vilar, 1982. 
revolucionario José Artigas como conductor de masas, pero también conducido por sus seguidores a tomar determinadas decisiones (1986). En esta línea, Ana Frega profundizó en las características de los liderazgos militares en la campaña, subrayando la importancia de sus alianzas con los diferentes sectores rurales al calor de las luchas por revolución y la conformación provincial y estatal, lo que les permitió negociar con las elites que disputaban por el poder central (2002 y 2008).

Conjuntamente, se desarrolló una línea de investigación enfocada en las instituciones de justicia y sus administradores en el Río de la Plata y en la frontera sur de los dominios portugueses durante la administración colonial y los primeros años de la construcción de los estados nacionales (Gelman 2000; Barral y Fradkin 2005; Comissoli 2015). Diversos trabajos ahondaron en las prácticas jurídicas y las formas gobierno de la campaña permitiendo una mejor comprensión del despliegue de las estructuras estatales en la región (Garavaglia 2009; Barrriera 2014).

A partir de estas propuestas, el objetivo del presente trabajo es indagar en los motivos detrás de la decisión del gobierno provincial de no respetar el fuero de los oficiales y reprender la recolección de firmas por parte de milicianos y vecinos de los pueblos del departamento de Maldonado en apoyo a Olivera. Para ello en la primera parte se enmarcará el ataque dentro de las disputas jurisdiccionales del departamento en un contexto que obligó al gobierno provincial a dar lugar a los reclamos de los notables locales. En la segunda parte se profundizará en la preocupación de las autoridades por la junta de firmas y la caracterización que hicieron del accionar de los vecinos que apoyaban a Olivera y de su relación con la autoridad militar local.

Se entiende que el episodio da cuenta de los límites del poder militar, así como de la vigencia de la institucionalidad local durante la construcción estatal, más allá de la inestabilidad típica de una guerra y del auge del bandelorismo rural. Asimismo, da cuenta de las dificultades de la imposición de nuevas formas de gobierno basadas en principios liberal-republicanos, que chocaron con antiguas prácticas y diferentes concepciones de autoridad, en un marco de construcción de nuevos liderazgos locales y de politización de los habitantes de la campaña.

\section{Guerra y conflictos jurisdiccionales: el reclamo de los notables de Maldonado}


El ataque de Orona al Consejo de Justicia de Maldonado puede inscribirse dentro de los conflictos jurisdiccionales entre las autoridades civiles y militares del departamento, y en especial en la serie de enfrentamientos entre el comandante militar Leonardo Olivera y los jueces de la ciudad. Se trata de un problema de larga duración en la región rioplatense, que resurgió con la revolución y la construcción de nuevos proyectos estatales, y cuyo trasfondo era el control de los hombres durante el reclutamiento y su movilización al frente de guerra, la ocupación del territorio y la explotación de sus recursos, así como las alianzas de los notables locales y los jefes militares con los diferentes proyectos políticos en disputa en la región rioplatense (cfr. Fradkin 2014; Frega 2007; Autor 2014).

En el caso de Maldonado los enfrentamientos entre sus autoridades se remontan al menos desde el comienzo de revolución artiguista. Las alianzas de los notables de la ciudad con las facciones que disputaban el poder central incidieron en la conflictividad del departamento. San Fernando de Maldonado fue de los primeros pueblos en reconocer la Junta de Buenos Aires (a cambio de la habilitación de su puerto) y sus notables estrecharon vínculos con los sectores que promovían una organización de las provincias bajo el principio de la unidad, en oposición a las propuestas federales defendidas por el artiguismo. Asimismo, las buenas relaciones de sus comerciantes con las fuerzas lusobrasileras fueron constante foco de discordia y desconfianza con los jefes militares del departamento. ${ }^{11}$

Las luchas por la posesión de la tierra fue otro de los motivos de estas disputas. Los integrantes del cabildo de Maldonado se mostraron reacios al reparto dispuesto por el Reglamento Provisorio de la Provincia Oriental para el Fomento de su Campaña y Seguridad de sus Hacendados de 1815. Juan de Uriarte, miembro del consejo atacado en 1828, integraba en 1816 la institución capitular mientras litigaba con un grupo de vecinos que ocupaban tierras en las inmediaciones del río Cebollatí. En dicho espacio Olivera tenía relaciones establecidas y reclutaba hombres frecuentemente (De la Torre, et al. 1969, 206).

\footnotetext{
${ }^{11}$ En oficio del 23 de mayo de 1828, meses antes del ataque, Orona le solicitó a Lavalleja que la correspondencia de su familia fuera enviada directamente al cuartel general, ya que donde se encontraba había «un monton de picaros Mas ynperiales q.e los mismos portug.s». Pedro Orona a Juan A. Lavalleja, Chafalote, 23 de mayo 1828, en Archivo General de la Nación, Archivo del General Juan Antonio Lavalleja, [AGJAL], Tomo III (Montevideo: El Siglo Ilustrado, 1941): 190.
} 
El perfil de los jueces y jefes militares del departamento parece reforzar estas posiciones entre la ciudad y el resto de su jurisdicción..$^{12}$ Los integrantes del extinguido Cabildo y del Consejo de Administración de Justicia de Maldonado se diferenciaron mayoritariamente por su dedicación al comercio, mientras que en los pueblos y villas existió una mayor diversificación de ocupaciones, destacándose una importante participación de los hacendados. En el caso de los jefes militares, predominantemente de origen americano, se dedicaron preferentemente a la ganadería o al comercio, y aunque figuran importantes poseedores de tierras, por lo general no gozaban de grandes fortunas. Para la mayoría el camino de las armas fue una forma de ascenso social y de relacionamiento con los notables locales y regionales (Delgado, 2017).

Casi no se registran casos de autoridades que ejercieron funciones civiles y militares al mismo tiempo o durante su trayectoria. Anaya sería uno de los casos, pero no ejerció como jefe militar en el departamento. Esta constatación permite pensar en cierto grado de cohesión de quienes ocuparon cargos de justicia en la ciudad, así como de los jefes militares del departamento, en tanto grupos separados por diferentes intereses, pero relacionados por sus vínculos con la notabilidad local y regional.

Los enfrentamientos entre los notables y Olivera se habrían iniciado cuando el jefe militar se levantó contra las autoridades cisplatinas en 1823 y fue denunciado por los cabildantes ante el Capitán General de la Provincia Cisplatina Federico Lecor. ${ }^{13}$ Luego las diferencias continuaron durante el reclutamiento de los vecinos del departamento para el frente en la guerra contra Brasil, a pesar de los intentos de regular la leva con la mediación de las autoridades civiles. En 1828 el consejo protestó por lo consideraron un arresto arbitrario de algunos vecinos vinculados con la notabilidad del departamento, que fueron reclutados forzosamente para el frente de guerra (Delgado, 2017).

\footnotetext{
${ }^{12}$ En términos generales, y al igual que otros espacios rioplatenses y del sur de Brasil, las autoridades civiles y militares se caracterizaron por pertenecer a los sectores medios y por su arraigo en la comunidad más allá de su origen, condición distintiva de una zona de frontera (cfr. Gelman 2000; Candioti 2010; Del Valle 2014; Comissoli 2015; Kühn et al. 2013). Los jueces letrados departamentales, cuyos cargos fueron creados en 1826 y suprimidos en 1827 , fueron los únicos formados en leyes y remunerados por su función.

${ }^{13}$ Sala Capitular de la ciudad de San Fernando de Maldonado y departamento de Maldonado al Capitán General del Estado, 4 de abril de 1823, AGNuy, Montevideo, AJ, Juzgado Letrado Departamental de Maldonado, Caja 20, s.f.
} 
Los hechos llegaron a un nivel máximo de tensión con el ataque de Orona. En esta oportunidad el gobierno de la provincia fue particularmente sensible a las demandas de los notables de Maldonado de que las autoridades militares respetasen su subordinación a la jurisdicción civil. Ante la gravedad de los hechos el gobernador delegado de la provincia, Luis Eduardo Pérez, no reconoció la conciliación alcanzada por Anaya y mandó quitar el fuero militar a Orona y sus oficiales y llevarlos ante un tribunal civil. ${ }^{14}$ La decisión era significativa por el peso que tenía en las fuerzas en armas la tradición del fuero. ${ }^{15}$

En correspondencia a Lavalleja, Pérez fundamentó su decisión en la necesidad de «dar una satisfacion a los Pueblos» para que no se dijera que «no mira p.r ellos»y refutar la idea que Lavalleja apadrinaba a Olivera al punto de que «hace lo q.e quiere, y queda impugne». ${ }^{6}$ Esta satisfacción se puede explicar por el papel de los pueblos en la conservación del orden en la provincia y en el reclutamiento de hombres y el abastecimiento del ejército. También puede estar relacionado con la convocatoria a elección de representantes de la hasta entonces Provincia Oriental. ${ }^{17}$ Como ha señalado Marcela Ternavasio en las elecciones los alcaldes y jueces locales eran muy importantes por el ascendente de las magistraturas en los vecinos de los pueblos (135). El ataque de Orona en Maldonado reabrió una crisis que el gobierno había intentado solucionar con la mediación de Anaya. Esta nueva situación puso en un lugar de debilidad a las autoridades del gobierno provincial ya que daba argumentos a los opositores para que sean apoyados por los notables locales.

\footnotetext{
${ }^{14}$ Luis Eduardo Pérez nació en Montevideo el 11 de octubre de 1774. Se inició en la vida política durante la invasión portuguesa de 1816. Luego participó en el llamado Congreso Cisplatino de 1821 como representante de San José, donde se votó la incorporación de la provincia al Reino de Portugal. Formó parte de los planes de sublevación impulsado por el Cabildo de Montevideo contra la dominación lusobrasilera y se incorporó a la invasión de Lavalleja en 1825. Tiempo después fue electo como representante por San José en la Sala de la Florida y ejerció el cargo de Gobernador Delegado de la Provincia desde 1827 hasta la conformación del Estado Oriental independiente en 1828. Posteriormente, en su calidad de presidente del senado ocupó en reiteradas ocasiones la jefatura del poder ejecutivo ante la ausencia del presidente Fructuoso Rivera (Fernández Saldaña, 997-998).

15 Esta fue de vital importancia en la conformación de las milicias durante el orden colonial y la conformación de los estados nacionales, y ofició en distintos momentos como una salvaguarda de sus integrantes, lo que entraba en conflicto con la justicia civil (Fessler 2018).

${ }^{16}$ Luis E. Pérez a Juan A. Lavalleja, Durazno, 25 de julio de 1828, en AGJAL, Tomo III (Montevideo: El Siglo Ilustrado, 1941): 292.

${ }_{17}$ Según Clarel de los Santos, desde 1825 las elecciones realizadas en territorio liberado del dominio brasileño dieron lugar «una relativa ampliación de la actividad política, redundaron en una notoria expansión de la ciudadanía, fomentaron un conjunto de prácticas electorales, estimularon definiciones y reagrupamientos de personajes notables en los diversos círculos, reanimando una disputa por el poder que llevaba cerca de veinte años» (14).
} 
Conjuntamente, existían razones estratégica vinculadas al lugar donde se dio el ataque, por lo que estaba en riesgo las posiciones alcanzadas por el Ejército Republicano de las Provincias Unidas con la victoria en la batalla de Ituzaingó. ${ }^{18} \mathrm{El}$ departamento de Maldonado fue una zona de avanzada del ejército brasilero, ya que estaba en el camino hacia Montevideo. ${ }^{19}$ En la isla Gorriti, ubicada frente a su puerto, existía un recinto fortificado que fue ocupado en reiteradas ocasiones por las fuerzas imperiales. Por lo tanto, era imperiosa una solución que evitara el desorden en las tropas y desguarneciera la defensa de la zona.

Por estas razones el 12 de agosto fue designado Alsina en calidad de juez comisionado por el gobernador delegado Luis Eduardo Pérez, para juzgar a Orona y sus oficiales por «sediciosos y perturbadores del orden»y «p.a destruir totalm.te los prestigios del desorden q.e aun pr. desgracias se conservan y hacen sentir en la Provincia».20 Probablemente el gobierno valoró de Alsina su experiencia en la administración de justicia, su formación y su condición de foráneo, características que se valoraban para el desarrollo de un sumario alejado de presiones e intereses locales. ${ }^{21}$

A partir del 27 de agosto de 1828, y durante casi dos semanas, Alsina realizó los interrogatorios. La lectura del expediente da cuenta de los vínculos entre las preguntas del juez y la preocupación del gobierno provincial y los jueces de Maldonado de poner coto a lo que consideraban reiterados atropellos del poder militar sobre la jurisdicción civil. Alsina procuró determinar las responsabilidades en el desconocimiento a las autoridades de justicia y en la recolección de firmas para las representaciones a favor de Olivera. El 2 de octubre en la villa del Durazno se hizo la lectura de los cargos que recayeron exclusivamente en el comandante interino Orona. El juez le indicó falsedades y contradicciones en su testimonio y lo hizo responsable de la orden de

\footnotetext{
${ }^{18}$ Localidad cercana a Rosario del Sur, en ese entonces parte de San Pedro de Río Grande del Sur, Imperio del Brasil.

$19 \mathrm{Al}$ momento del ataque de Orona, Olivera estaba encargado de ayudar en el abastecimiento de la flota al mando del ejército republicano en la laguna Merín, límite de la jurisdicción departalemtal con el Brasil, cuyo principal objetivo era cortar las incursiones del ejército enemigo y su provisión de recursos (César Pintos Diago 148-155)

${ }^{20}$ Luis E. Perez al Fiscal General Alcina, Durazno, 12 de agosto de 1828, en Causa contra el Teniente Coronel Pedro Orona, 1828, AGNuy, Montevideo, Ex-AGA, Libro 1378, f. 22.

${ }^{21}$ Alsina era originario de Buenos Aires, formado en leyes y en esos momentos, al igual que Anaya, miembro de la recién creada Cámara de Apelaciones. Tenía experiencia como juez letrado en los departamentos de Santo Domingo Soriano, Colonia y Paysandú (Cuadro 31).
} 
arresto, exonerando de toda culpa a sus oficiales. ${ }^{22}$ Teniendo en cuenta que fue uno de los ejes de su sumario, queda la interrogante sobre los motivos de que no haya no establecido responsabilidad alguna en la recolección de firmas.

La noticia de la Convención Preliminar de Paz entre las Provincias Unidas y Brasil, con la intermediación de Gran Bretaña, y que supuso el reconocimiento de la Provincia Oriental como estado independiente, dio la oportunidad al gobierno de sobreseer la causa, liberar a los oficiales y desterrar a Oroná a Buenos Aires. ${ }^{23}$ El gobernador Pérez en correspondencia con Lavalleja le informó que despacharía a los oficiales para «que se vayan con Dios», ya que la paz era una oportunidad para solucionar dicho diferendo: «quedamos bien y se corta este asunto que tanto nos ha incomodado», añadió. ${ }^{24}$

El juicio puede verse como un logro de las autoridades de justicia de Maldonado. ${ }^{25}$ La posición de sus notables se vió reforzada al punto que propusieron la elección del coronel Pablo Pérez como nuevo jefe militar del departamento, una atribución que por lo general era las autoridades centrales pero que en este caso decidieron delegar. ${ }^{26}$ Ambos casos dan cuenta de los alcances de la trama de intereses entre los notables locales y las autoridades de la provincia, vínculos que permitieron a las instituciones de los pueblos limitar la fuerza militar y hacer valer sus reclamos, más allá del peso de la guerra y la militarización del territorio oriental. ${ }^{27}$

\footnotetext{
22 Lectura de cargos por la causa contra Orona, Villa de San Pedro del Durazno, 2 de octubre de 1828, Causa contra el Teniente Coronel Pedro Orona, 1828, AGNuy, Montevideo, Ex-AGA, Libro 1378, fs. 121vta127.

${ }^{23}$ Según el historiador Paul J. Vanderwood, para el caso de bandolerismo en el México de mediados del siglo XIX, «la amnistía es el modo en que el Estado (y también la Iglesia) prefiere, por lo general, negociar con los rebeldes. Puede optar por la amnistía en vez de la ejecución puesto que aquélla, desde el punto de vista del Estado, proporciona un ejemplo saludable al resto de la población, reincorporando a los rebeldes a la vida civil con un reconocimiento público y franco de la autoridad gubernamental. De esta forma, la amnistía se convierte en un renovado voto de lealtad a la autoridad y, por ende, en un reconocimiento de su legitimidad, que es el tipo de obediencia que aquellos que gobiernan en realidad, desean de sus súbditos» (129).

${ }^{24}$ Luis Eduardo Pérez a Juan Antonio Lavalleja, Durazno, 6 de octubre de 1828, Boletín Histórico, [Montevideo], abr-dic.1954: 142, Estado Mayor del Ejército, Uruguay: 63.

${ }^{25}$ De esta forma se entiende la resignación que meses después Olivera le manifestó a Lavalleja sobre su atraso en una reunión de fuerzas. En correspondencia fechada el 3 de octubre de 1828, explicó que el motivo se debía a que «como bajo un contrato» no podía «tomar mano» en la recolección de caballos reyunos y armas, sufrimiento «todo y todo a fin de que no molesten a Vd.». Leonardo Olivera a Juan Antonio Lavalleja, Rocha, 3 de octubre de 1828, Boletín Histórico, [Montevideo], abr-dic. 1954: 63, Estado Mayor del Ejército, Uruguay: 136.

${ }^{26}$ Gobierno Delegado al alcalde del Departamento de Maldonado, Copia N. ${ }^{\circ}$ 5, Durazno, 18 de setiembre de 1828, Boletín Histórico, [Montevideo], abr-dic. 1954: 63, Estado Mayor del Ejército, Uruguay: 115.

${ }^{27}$ Según Halperin Donghi durante la formación de las milicias urbanas a la luz de la crisis del orden
} 


\section{Antiguas prácticas y formas de autoridad en la campaña}

Como se indicó anteriormente, durante el interrogatorio el juez Alsina tuvo particular interés en establecer las responsabilidades en la recolección de firmas para las representaciones en apoyo a Olivera. Su seguimiento permite profundizar en las concepciones de los protagonistas sobre el gobierno de los pueblos, así como de la autoridad de los jefes militares y su relación con sus subordinados y vecinos del departamento. Al igual que en otras jurisdicciones, la preocupación de los notables de Maldonado y las autoridades provinciales por este tipo de acciones colectivas da cuenta del rechazo que generaba la politización de los oficiales de la milicia y los habitantes de la campaña (cfr. Fradkin 2005).

La declaración de Orona en el expediente da cuenta del origen de dos representaciones. Según el teniente coronel, el 24 de junio, luego de que Olivera fuera mandado marchar al frente junto al ejército republicano, los comandantes del escuadrón José Suarez, Ventura González y el de la milicia pasiva José Machado presentaron un oficio donde protestaron por el alejamiento de su jefe, con una presentación adjunta firmada por los soldados y dirigida a Lavalleja. Luego, el comandante de la milicia pasiva Tomás Corbo, Miguel Salalleta, Joaquin Paez, Ramón Silva, José Abreu y «otros dos que no recuerda», solicitaron permiso para redactar otra representación con el mismo objetivo que la anterior. Orona los autorizó y los oficiales empezaron a juntar firmas en las villas de Rocha, Minas y San Carlos y la ciudad de Maldonado, donde se designaron como comisionados a los vecinos Nicolas Rada, José Tabares y Antonio Silva. ${ }^{28}$

Según Orona, la iniciativa surgió por el crimen que se le imputaba a Olivera «en los papeles publicos» y que «los vecinos solo querian demostrar la necesidad y servicios del expresado Sor Olivera».29 En comunicación fechada el 28 de junio, el jefe interino dio cuenta de los problemas que tuvo para reunir a los oficiales que estaban «subcribiendo en otra por separado inclusibe todo el vecindario», y que todo se precipitó entre el 24 y 28 de junio al conocerse la noticia de que Olivera no volvía al

colonial en el Río de la Plata se produjo una «militarización» de la sociedad que permitió un mayor peso político a los jefes militares en la organización de los nuevos proyectos estatales en la región (Halperin Donghi 152-181). Para una actualización de dicha noción y sus límites a la luz de los últimos avances de la historiografía, cfr. Rabinovich 11-42.

${ }^{28}$ Causa contra el Teniente Coronel Pedro Orona, 1828, AGNuy, Montevideo, ExAGA, Libro 1378, f. 35. 29 Ídem. 
departamento. En dicha ocasión Orona le indicó a Lavalleja que «nada menos q.e Ami ya me tienen loco p.r q.e aqui no se combersa de otra cosa, sino del Coron.l Olibera».30

La junta de firmas para elevar representaciones era una práctica común en el Río de la Plata, relacionada con la tradición del derecho de petición, considerada como una forma legítima de participación de los vecinos en la discusión pública (Ternavasio 2001). Tanto Olivera como Anaya participaron en las asambleas de vecinos y en la remisión de las actas firmadas en apoyo a la disolución de la Sala de Representantes en 1827. En los intercambios epistolares que mantuvieron antes del golpe manifestaron su preocupación por cumplir con la formalidad y legalidad requerida. El 26 de ese mes Olivera le informó a Lavalleja que al momento de reunir a los vecinos «se selebró la Acta con toda desencia y livertad, p.a q.e los cavilosos no tubiesen q.e dar por ilegal el Acto».31 Por su parte, el 31 de octubre Anaya envió a Olivera el acta de la reunión de los vecinos y le expresó su creencia de que ésta estaba «bastantemente vestida con el numero de firmas que informan el sufragio de este vecindar.o p.a reputarse con todo valor legal que corresponde». Además, le pidió que la enviase con celeridad a Durazno, donde debía ser impresa y puesta en circulación, en caso de que hubiese otros «pueblos con reparos de declarar su voto Libre», a pesar de que «en los demas del departam.to no se huviesen pronunciado». $3^{2}$

Este antecedente permite entender la posición de los notables de Maldonado y sus temores manifestados en el expediente por la forma en que los vecinos de la campaña se involucraron en las disputas jurisdiccionales. Un ejemplo en este sentido es la crítica que Anaya hizo a Orona por haber dado lugar a la introducción de «ideas subercivas del orden q.e perturban la tranquilidad del Pueblo» y haber seducido «avitantes a prestar firmas subrrepticiamente, en una reprecentacion, cuya tendencia es desconocida a la Autoridad Civil q.e le precide».33

\footnotetext{
${ }^{30}$ Pedro Orona a Juan A. Lavalleja, Rocha, 29 de junio de 1828. Archivo General de la Nación, en AGJAL, Tomo III (Montevideo: El Siglo Ilustrado, 1941): 256.

${ }^{31}$ Leonardo Olivera a Juan A. Lavalleja, San Carlos, 29 de octubre de 1827, en AGJAL, Tomo II (Montevideo: El Siglo Ilustrado, 1935): 194.

$3^{2}$ Carlos Anaya a Leonardo Olivera, Maldonado, 31 de octubre de 1827, AGJAL, Tomo II (Montevideo: El Siglo Ilustrado, 1935): 201-202.

33 Carlos Anaya al Teniente Coronel Comandante Militar Pedro Orona, Maldonado, 1 de julio de 1828, Causa contra el Teniente Coronel Pedro Orona, 1828, AGNuy, Montevideo, Ex-AGA, Libro 1378, fs. 7-9.
} 
Para los jueces estas acciones escapaban a su control y entraban en conflicto con la noción de representación que se intentaba establecer en la región platense. Se las asimilaba con las formas «asamblearias» que surgieron con la revolución y que durante la década de 1820 fueron denunciadas como expresiones anárquicas, que fomentaban el espíritu de partido o de facción y que iban contra el bien común. Estas debían ser superadas a través de formas de gobierno representativas establecidas por medio de elecciones directas con amplia participación popular, y en los cuales las autoridades de justicia tenían un rol fundamental (Ternavasio 2001; Di Meglio 2006; De los Santos 2017).

Este principio se basó en una lectura del republicanismo predominante luego de la crisis del proyecto centralista de Buenos Aires en 1820, según la cual, el sistema representativo protegía los derechos y libertades de los ciudadanos y los blindaba de propuestas más participativas e igualitarias (Di Meglio 2009).34 En este sentido se expresó el comisionado Anaya cuando le indicó a Orona que la junta de firmas contradecía «alas Leyes vigentes, y a los principios Republicanos», más allá de que expresara la voluntad de sus habitantes:

"La voluntad del Pueblo es la suprema Ley, por un axioma del mundo ilustrado; pero también es una verdad inconensa q.e el abuso de esa misma ley, una ves q.e se prentenda inclinarla o persuadirla vaxo formas clandestinas y ceductivas, es imperdonable a sus autores. Este es el organo de la fatalidad, q.e corrompe la moral publica, y ataca las livertades mas sagradas del ciudadano».35

Este cambio de postura de Anaya respecto a la junta de firmas puede estar relacionado por su rol de mediador como por sus estrechos vínculos con la notabilidad de Maldonado. También puede explicar su acento en la responsabilidad de Orona por las «formas clandestinas». En la mencionada proclama que redactó para dar por finiquitado el conflicto subrayó que la milicia activa fue «impulzada por la exaltacion

\footnotetext{
34 A diferencia del concepto de república manejado durante la colonia más vinculado al gobierno de la cosa pública y la jurisdicción de los pueblos (Entin 2014).

35 Carlos Anaya al Teniente Coronel Comandante Militar Pedro Orona, Maldonado, 1 de julio de 1828 , en Causa contra el Teniente Coronel Pedro Orona, 1828, AGNuy, Montevideo, Ex-AGA, Libro 1378, fs. 79 .
} 
de su Gefe interino que marchando a la Caveza vajo un aspecto de horror havian herido su patriotismo por equivocados conceptos de desagravio». .36

Por su parte, los miembros del consejo de Maldonado denunciaron esta acción ante el gobierno provincial. Su argumento era que la «autoridad militar» estaba auspiciando «esta forma de arrancar firmas», procedimiento «que es despreciado por los Ciudadanos». Más allá de que reconocieron no estar informados del contenido de las representaciones, para las autoridades el acto no representaba el deseo de los vecinos, quienes habrían firmado por ignorancia, «por compromiso» o por la imposición violenta de los jefes militares. 37

Esta conclusión a la que llegaron las autoridades civiles parte de una caracterización recurrente en los conflictos jurisdiccionales, muy similar a la que varios contemporáneos hicieron sobre los jefes militares surgidos con la revolución, los denominados «caudillos», y su relación con los habitantes de la campaña. ${ }^{38}$ Incluso varios historiadores la incorporaron con algunos matices como categoría, pero sin problematizarla (cfr. Pivel Devoto 1942; Magariños 1948; Lynch 1993).39 Sin embargo, y como se ha señalado en la introducción, en las últimas décadas diferentes historiadores han cuestionado esta caracterización de los líderes militares como agentes distorsivos en la conformación de instituciones legales y republicanas. A partir de análisis más centrados en comprender sus acciones en el marco de la cultura política rioplantense, se ha demostrado que sus liderazgos no siempre se establecieron a través de relaciones políticas de sometimiento con sus bases (Goldman 1993). A la luz de estas nuevas interpretaciones se puede encontrar razones que contradicen la versión de las autoridades locales. Tanto los oficiales de milicias como los vecinos del departamento tenían motivos suficientes para firmar por su propia voluntad. Si se analiza la carrera

\footnotetext{
36 Proclama de Carlos Anaya a los Habitantes del Departamento de Maldonado, Maldonado, 12 de julio de 1828, en Causa contra el Teniente Coronel Pedro Orona, 1828, AGNuy, Montevideo, Ex-AGA, Libro 1378 , f. 17 .

37 Copia de Consejo de Administración de Justicia de Maldonado al ministro de la Cámara de Apelaciones y Comisionado por el Gobierno Delegado, Carlos Anaya, Maldonado, 10 de julio de 1828, en Causa contra el Teniente Coronel Pedro Orona, 1828, AGNuy, Montevideo, Ex-AGA, Libro 1378, f. 6.

${ }^{38} \mathrm{El}$ caso más célebre es la obra de «Facundo o civilización y barbarie en las pampas argentinas» escrita por Domingo Sarmiento, escritor y político argentino, y publicada en 1845.

39 En el caso de los caudillos locales Mateo Magariños de Mello ha asimilado las comandancias militares de los departamentos a poderes «feudales», donde se ejercía la autoridad de forma discrecional «sin más límites que el de la buena o mala voluntad». Según el autor, durante el período iniciado con las revoluciones su autoridad «fue frecuentemente despótica e irresponsable» y la incapacidad del gobierno central para hacerse respetar les dio «una autonomía casi sin límites» (253).
} 
de la revolución de Olivera se pueden encontrar los vínculos que el jefe militar tejió durante las guerras de independencia. $4^{\circ}$

Como han advertido Valentina Ayrolo, Ana Laura Lanteri y Alejandro Morea, la experiencia de la guerra permitió construir una idea de sacrificio por el bien común que cimentó la legitimidad política de los oficiales militares en el Río de la Plata, además de proyectar sus carreras para las siguientes décadas con la construcción de nuevos vínculos, recursos y jerarquías (Ayrolo, et al. 2011). La foja de servicios de Olivera da cuenta de la construcción de este capital. Su trayectoria se inició en 1811 con su ingreso en las fuerzas artiguistas hasta que cayó prisionero en manos portuguesas y fue recluido en una cárcel de Río de Janeiro (Seijo 67). A poco de ser liberado participó en la sublevación contra el dominio lusobrasilero de la provincia promovida por el Cabildo de Montevideo en 1823. Reclutó hombres y caballadas por San Carlos y Rocha, hecho que significó su primer enfrentamiento con el Cabildo de Maldonado, como se mencionó anteriormente.

En 1825 se sumó al levantamiento de Lavalleja y en mayo fue nombrado jefe de milicias del departamento de Maldonado. Durante la guerra contra Brasil se construyó un buen prestigio entre los vecinos por su defensa de la zona. Algunos testimonios dan cuenta de que la guerra para los habitantes de la frontera fue particularmente violenta y la presencia de tropas al mando de Olivera significó cierta seguridad en la posesión de sus bienes. ${ }^{41}$ Los vecinos de la ciudad de Maldonado también podían sentirse en deuda con el comandante y sus milicias por su participación en la expulsión de las fuerzas enemigas apostadas en las playas de la punta del este en 1827.42

\footnotetext{
${ }^{40}$ La expresión fue acuñada por Halperin Donghi al exponer su tesis de que la revolución generó un espacio para sectores relegados durante el dominio colonial para desarrollar una «carrera» en la administración pública, a partir de su capital político y su experiencia militar, lo que a su vez permitió su «promoción individual» y ascenso social (2005).

${ }^{41} \mathrm{El} 31$ de octubre el comisario de Rocha Juan Bonifacio García le dió parte a Olivera de la exposición del vecino Agustín Pirez sobre los temores del pueblo «al verse amagado por unos enemigos q.e no tendran con ellos la mas lebe consideracion». Agregó que esperaban del comandante del departamento y de las fuerzas de su mando que «les preste seguridad de sus personas, y vienes, pues todo ello lo consideran perdido", a lo que García respondió que Olivera estaba preocupado por ellos. Juan Bonifacio García a Leonardo Olivera, Rocha, 31 de octubre de 1827, en AGJAL, Tomo II (Montevideo: El Siglo Ilustrado, 1935): 203-204.

${ }^{42}$ Brito del Pino, José, Diario de la Guerra del Brasil. Agosto de 1825 a noviembre de 1828. Montevideo, s.e., 1956: 210-211.
} 
Olivera también demostró tener la capacidad de organizar una fuerza de alrededor de 500 hombres (entre milicianos voluntarios e individuos reclutados a la fuerza), y alcanzó algunos éxitos militares, como asegurar el frente durante la incursión del ejército de Alvear en Río Grande y la toma de la Fortaleza de Santa Teresa en 1825 y 1828. Como comandante del departamento construyó un entramado de oficiales similar a lo que Beatriz Bragoni llamó el gobierno de amigos sólidos para la organización del ejército del general José de San Martín. Se trató de un esquema de poder que se basaba en la instalación en la administración política y militar de gente leal a la revolución, logrando una relativa coherencia, gran alcance territorial y muchas influencias para movilizar hombres y recursos (Bragoni 105).

La experiencia de la guerra parece haber fortalecido estos lazos. En ocasión de la protesta de los milicianos a inicios de 1828, Olivera informó a Lavalleja que sus oficiales elevaron un escrito en su favor por ser «un Gefe q.e aprincipado la Revolución» y que los vecinos pretendían hacer lo mismo con otra representación. Aseguró que volvería «bolando con el fin [de] apagar todo» y que luego continuaría su marcha, pero le suplicó que «disimule algo» con la representación y mire a los firmantes con compasión, ya que «mis pobrez compañeros escazos de cono cimientos puedan hablar [con] algun desatino llevado de la pazion de un jefe q.e tanto los a apreziado y padezido con ellos en toda la Revolución».43

Parte del éxito de este entramado de intereses puede estar también relacionado con la capacidad de Olivera de recompensar a sus oficiales y a los vecinos de la campaña que lo apoyaron con recursos para el abastecimiento de sus fuerzas. Muchos se vieron beneficiados con la distribución de parte del botín de seis mil cabezas de ganado que obtuvo en la guerra contra el Imperio del Brasil. Si bien el gobierno había dispuesto una quita del ganado extraído para beneficio del Estado, Olivera explicó que no pudo cumplir con la orden por haberle llegado tarde la comunicación y en consideración con «el empeño y entusiasmo» con que su milicia «se prestó a llevar las armas».44

43 Leonardo Olivera a Juan A. Lavalleja, Costa del Olimar, 5 de febrero de 1828, en AGJAL, Tomo III Montevideo: Archivo General de la Nación, 1941): 361.

44 Leonardo Olivera al Comandante General de Armas, San Carlos, 28 de junio de 1827, en Boletín Histórico, [Montevideo], ene-feb. 1951: 46, Estado Mayor del Ejército, Uruguay: 105-106. 
Esta recompensa abrió la oportunidad para un ascenso social tanto de Olivera como para sus oficiales. Según el diario de guerra de Brito del Pino, Lavalleja informó en un oficio a Pérez fechado el 29 de octubre de 1828 de una solicitud de Olivera para que se le facilite el Rincón de Pan de Azúcar para colocar su ganado junto al de «un Comandante, dos Capitanes, cuatro tenientes, un Alférez, y un Sargento de aquella milicia».45 La solicitud fue concedida, pero a la espera de lo que dictara el nuevo «Gobierno general permanente» sobre propiedades públicas. 46

Estos lazos le permitieron operar durante las luchas por la posesión de tierras y ganado durante la década de 1820, en un contexto que se reforzaron las relaciones entre ocupantes y caudillos como forma de mantenerse en la posesión de los campos (De la Torre, et al. 1972). En este sentido, Frega ha demostrado el papel que la defensa de los ocupantes de tierras tuvo en la construcción del liderazgo militar de Fructuoso Rivera luego de la derrota artiguista y la consolidación del dominio luso-brasilero en la Provincia Oriental entre 1820 y 1825 (2008). En el caso de Olivera apenas dos años después del ataque participó junto a Lavalleja en la defensa de vecinos de Solís Grande en el departamento de Maldonado. Ante el reclamo de posesión del hacendado Félix de Álzaga recolectó firmas y obtuvo el amparo judicial a los ocupantes (De la Torre et al., 1972, 116).

Estos atributos y lazos sólidos de Olivera contribuyeron a la formación de su carisma a nivel del departamental, característica imprescindible de los líderes rioplatenses surgidos con la crisis colonial y la revolución (Di Meglio 2006). Condición de la que Orona carecía dada su situación de recién llegado, y que tal vez permita entender la reticencia y poca convicción con que los oficiales implicados en el ataque de 1828 recibieron sus órdenes de arresto. Según la declaración del oficial Pedro Gaitan, algunos miembros de la partida como el mayor Suárez se sintieron defraudados y solicitaron el 12 de junio una reunión en casa de Orona. Allí le exigieron explicaciones

\footnotetext{
45 Brito del Pino nació en Montevideo en 1797. Era hijo de un militar español, José Pérez Brito y de María Josefa del Pino (hija del gobernador de Montevideo y virrey del Río de la Plata Joaquín del Pino). En 1825 se incorporó a la invasión de Lavalleja y poco después fue designado como ayudante del Estado Mayor General del Ejército Republicano. Luego ascendió a ayudante de campo y a primer oficial de secretaria, posición privilegia desde la cual redactó un diario donde dio cuenta de la vida cotidiana de la jefatura de la guerra. Se publicó en la Revista Histórica en 1910. La versión consultada ha sufrido la compaginación y edición de su nieto Juan José Brito del Pino Berro.

46 Brito del Pino, 385-386. En 1855 Olivera declaró ante el juzgado de Paz de San Carlos que los terrenos de Pan de Azúcar estaban arrendados y valían \$2.500 (Seijo 70).
} 
sobre las órdenes de prisión y la supuesta negación del jefe militar de dichas medidas al consejo. Orona habría contestado negando tal versión, que «en efecto las abia dado» y que sintió «q.e no las hubiesen cumplido» y que por eso «les recombino seriem.te».47

Asimismo, Gaitan relató un encuentro que tuvo días antes del ataque con otros oficiales en una tertulia de señoras. Desde la calle el capitán Eufemio Isaurral, quien estaba junto a Joaquin Diego Pereyra, Eusebio Gomez y Joaquin Tabares, lo llamó y le previno de los planes de Orona. Según su testimonio, contestó que se oponía a dicho movimiento «p.r q.e no queria comprometerse en un prollecto de igual trascendencia» ya que Orona «no inbestia facultad alguna p.a perseguir aquellos majistrados». $48 \mathrm{La}$ declaración deja en evidencia ciertas contradicciones en la versión de los demás oficiales y vecinos que negaron conocer la condición que revestían las autoridades civiles o los planes de Orona de arrestarlos, lo que puede estar relacionado con sus estrategias de evitar su castigo y responzabilizar al jefe interino de todas las acciones. También permite pensar en algunos espacios de discusión y decisión de los oficiales y miembros de las milicias, quienes podían ir en contra de lo dispuesto por sus autoridades superiores si se violaban ciertos principios (cfr. Di Meglio 2006, 178).

La condición casi de foráneo de Orona como su reciente llegada al mando de la milicia no le habría permitido establecer vínculos con sus oficiales, ni probablemente con el vecindario de Maldonado. En el interrogatorio Orona confesó ser natural de la provincia de Salta y vecino de la ciudad de Buenos Aires. Inició sus servicios en la batalla de las Piedras en 1811 como sargento segundo en el Cuerpo de Patricios, y fue ascendido a alférez e incorporado a los Dragones de la Patria en junio de ese mismo año. Luego estuvo presente en el sitio de Montevideo, combatió en la batalla del Cerrito y en la isla de Martín García por cuya acción ascendió al grado de capitán (Carranza 1962, 237-239).

Como indica Raúl Fradkin en su análisis del expediente que se levantó contra Cipriano Bénitez, líder de una montonera que actuó en los pueblos de Navarro y Luján en 1826, la fama terminaba siendo el principal medio de prueba en un expediente judicial. La opinión que se tenía del acusado por parte de los vecinos era prueba «del entramado social en que estaba inscripto el sujeto» y lo que definía «si podía ser

47 Causa contra el teniente coronel Pedro Orona, 1828, AGNuy, Montevideo, Ex-AGA, Libro 1378, f. 62vta. 48 Ídem. 
considerado - legal y socialmente- como parte de esa laza comunidad que configuraba cada partido rural o «perjudicial» a ella» (2006, 81). Estas dificultades sumadas a su condición de jefe de la partida probablemente sean las principales causas de haber tenido que enfrentar los cargos que le imputó el juez Alsina y el destierro de la provincia luego del sobreseimiento de todos los implicados.

\section{Conclusiones}

En el presente trabajo se analizó el juicio a un ataque militar que se dio en un contexto regional de auge de las montoneras y el bandolerismo social (Fradkin 2006; Ayrolo 2008). Si bien no se puede definir el atentado como parte de estas expresiones (tampoco lo hicieron las autoridades), se lo puede relacionar como parte de los conflictos que caracterizaron a la política del Río de la Plata y, en particular, a la Provincia Oriental, luego de la revolución. Detrás del aparente problema jurisdiccional se entremezclaron antiguas y modernas concepciones sobre la autoridad, la reivindicación de privilegios de los habitantes del departamento en función de su inserción en la comunidad local, y las formas de acción colectiva consideradas legítimas. En este sentido, las reacciones a la junta de firmas para la representación en apoyo a Olivera muestra el temor de los notables de Maldonado a politización de los vecinos de la campaña y a prácticas que favorecían la autoridad de un jefe militar que les había disputado posiciones de poder y el control de los recursos del departamento.

El seguimiento de la trayectoria militar de Olivera da cuenta de las particularidades de su liderazgo a nivel local, en una zona de fronteras, matizando así la caracterización de los caudillos locales hecha por ciertos testimonios de época y luego por la historiografía tradicional. De este modo se puede ver como genuino el apoyo de algunos vecinos a las representaciones y comprender las dificultades de Orona en hacerse obedecer por sus oficiales durante el ataque al Consejo de Administración de Justicia. El capital obtenido por Olivera sobre la base de su experiencia militar durante la revolución y los lazos sólidos establecidos con sus milicianos durante la guerra formaron parte del carisma que tenía entre los habitantes del departamento. Su autoridad se construyó a través de una compleja trama de relaciones establecidas durante la guerra y las luchas por la posesión de tierras y ganado, y sobre la base del respeto de determinados principios y a la retribución de sacrificios por una causa. 
El seguimiento del juicio da cuenta de la preocupación que generó en el gobierno y las máximas autoridades provinciales, a pesar de las escasas menciones en la historiografía uruguaya y en los trabajos de historiadores locales. Asimismo, deja en evidencia la relación de los enfrentamientos al interior del departamento con las disputas por el poder provincial y los diferentes proyectos de organización estatal en la región rioplatense. Es indiscutible que la resolución del juez Alsina significó un triunfo para los notables de Maldonado y un límite a la autoridad militar de Olivera, dando cuenta de la vigencia de la institucionalidad de los departamentos de la provincia, más allá del contexto de guerra, que aumentó el peso de los jefes milicianos en el gobierno de los pueblos.

La resolución del episodio y sus implicancias se constituye en un elemento más para la comprensión de la organización departamental que se dio el Estado Oriental independiente desde 1830, caracterizada por la centralización del gobierno de los pueblos de la campaña (Delgado, 2017). Asimismo, el trabajo deja abiertas algunas cuestiones y problemas a profundizar, como el perfil de los oficiales de la partida de Orona y su trayectoria como milicianos, las características de los vecinos que apoyaron las representaciones, la composición social de la milicia del departamento (y en especial, la de los miembros de la tropa) y su relación con las prácticas estudiadas.

\section{Obras citadas}

\subsection{Fuentes}

Archivo General de la Nación (agnuy), Montevideo, Uruguay. Fondo Ex-Archivo General Administrativo, Libro 1378, Causa contra el Teniente Coronel Pedro Orona, 1828.

AGNuy, Montevideo, Archivo Judicial (AJ), Juzgado Letrado Departamental de Maldonado, Caja 23.

Archivo General de la Nación, Archivo del General Juan A. Lavalleja, Tomo II (Montevideo: El Siglo Ilustrado, 1935); Tomo III (Montevideo: Archivo General de la Nación, 1941).

Armand Ugón, E., et al., Compilación de leyes y decretos, 1825-1834, Tomo I (Montevideo: s.d., 1930).

Boletín Histórico, [Montevideo], ene-feb. 1951: 46 y abr-dic. 1954: 63, Estado Mayor del Ejército, Uruguay.

Brito del Pino, José, Diario de la Guerra del Brasil. Agosto de 1825 a noviembre de 1828. Montevideo, s.e., 1956.

«Memoria autobiográfica de Carlos Anaya», Revista Histórica, 103-105 (Montevideo: Barreiro y Ramos, 1964): 604-776. 


\subsection{Bibliografía}

Autor, 2014, 55-84 y 2017.

Ayrolo, Valentina, et al., «Repensado la «Carrera de la Revolución». Aportes a la discusión sobre las trayectorias políticas entre la Revolución y la Confederación (Argentina. 1806-1861)», Estudios Históricos. 7 (octubre 2011): 1-28.

Ayrolo, Valentina, «Hombres armados en lucha por poder. Córdoba de la pos independencia», Estudios Sociales. 35 (segundo semestre 2008): 23-60.

Barral, María E. y Raúl O. Fradkin, «Los pueblos y la construcción de las estructuras de poder institucional en la campaña bonaerense (1785-1836)», Boletín del Instituto de Historia Argentina y Americana «Dr. Emilio Ravignani». 27, (1er. Semestre 2005): 7-48.

Barrán, José, «Artigas: del culto a la traición», Brecha. 35 (20 de junio de 1986): 11.

Barrriera, Darío G., "El gobierno de los campos entre el reformismo borbónico y la política de los vecinos: partidos, distritos y jueces delegados (Santa Fe, 17891808)". Gobierno, justicias y milicia. La frontera entre Buenos Aires y Santa Fe (1730-1820), Barriera D. G. y R. Fradkin, coords. La Plata: Universidad N. de La Plata, 2014: 119-155.

Bleil, Susana y Fabricio Prado, «Brasileiros na fronteira uruguaia: economía y política no século XIX», Segundas Jornadas de Investigación de AUDHE. (1999). Recuperado de: www.audhe.org.uy/Jornadas.../II.../ Bleil\%20adhue-99-2.doc.

Bragoni, Beatriz, «Guerreros virtuosos, soldados a sueldo. Móviles de reclutamiento militar durante el desarrollo de la guerra de independencia», Dimensión Antropológica. 35 (set- dic. 2005): 95-138.

Carranza, Anjel Justiniano, Campañas navales de la República Argentina, Volumen I, Tomos 1 y 2, Historia naval argentina, Serie $B, N .^{o}$ 2. Buenos Aires: Secretaria de Estado de Marina Subsecretaria Departamento de Estudios Históricos Navales, 1962.

Chiaramonte, José Carlos, «La antigua constitución luego de las independencias, 1808-1852», Desarrollo Económico. 199 (octubre-diciembre 2010): 349-359.

Comissoli, Adriano, «Justiça ordinária e Justiça profissional na América Portuguesa, com especial mençao a capitania do Rio Grande de Sao Pedro (1749-1832)». Uma história social e cultural do Direito, da Justiça e da Politica. Do antigo regime ibero-americano a contemporaneidade latino-americana, Andrea Reguera y Eliane Cristina Deckman Fleck org. Sao Leopoldo: Oikos, Editoria Unisinos, 2015: 284-305.

Cuadro Cawen, Inés, «La crisis de los poderes locales. La construcción de una nueva estructura de poder institucional en la Provincia Oriental durante la guerra de independencia contra el Imperio del Brasil (1825-1828)». Historia regional e independencia del Uruguay, Ana Frega, coord. Montevideo: Ediciones de la Banda Oriental, 2009: 65-100.

Delgado, Santiago, «Pueblos de frontera, fuerzas en armas y construcción del Estado. El departamento de Maldonado entre 1820 y 1838», Tesis de maestría en Ciencias Humanas-Opción Historia Rioplatense, Montevideo: Universidad de la República-Facultad de Humanidades y Ciencias de la Educación, 2017. 
De la Fuente, Ariel, "“Gauchos", "Montoneros" y "Monteneras"». Caudillismos rioplatenses. Nuevas miradas a un viejo problema, Noemí Goldman y Ricardo Salvatore comp. Buenos Aires: Eudeba, 1998: 267-294.

De la Torre, Nelson et al, Después de Artigas (1820-1836). Montevideo: Ediciones Pueblos Unidos, 1972.

De la Torre, Nelson, et al, La revolución agraria artiguista (1815-1816). Montevideo: Ediciones Pueblos Unidos, 1969.

De los Santos Flores, Clarel, Elecciones entre sables y montoneras. Legitimaciones, ciudadanías y representaciones políticas en la Provincia/Estado Oriental del Uruguay, 1825-1838, Tesis de maestría en Ciencias Humanas-Opción Historia Rioplatense, Montevideo: Universidad de la República, 2017.

De Salterain y Herrera, Eduardo, «Lavalleja. La redención de la patria». Revista Histórica. XXVI (octubre de 1956): 166-186.

Di Meglio, Gabriel, «Un ejército de muchos nombres. La difícil formación de las fuerzas militares rioplatenses en la guerra entre las Provincias Unidas y el Imperio del Brasil», Claves. Revista de Historia. 7 (julio-diciembre 2018): 127-162.

Di Meglio, Gabriel, «República. Argentina-Río de la Plata», Diccionario político y social del mundo iberoamericano. La era de las revoluciones, 1750-1850 [Iberconceptos-I], Javier Fernández Sebastián dir. Madrid, Fundación Carolina, Sociedad Estatal de Conmemoraciones Culturales, Centro de Estudios Políticos y Constitucionales, 2009: 1270-1281.

Di Meglio, Gabriel, Viva el bajo pueblo! La plebe urbana de Buenos Aires y la política entre la Revolución de mayo y el rosismo. Buenos Aires: Prometeo, 2006.

Entin, Gabriel, «República y Federalismo en América del Sur, entre la Monarquía hispánica y las revoluciones de Independencia». Entre Mediterráneo y Atlántico. Circulaciones, conexiones y miradas, 1756-1867, Antonino De Francesco, Luigi Mascilli Migliorini, Raffaele Nocera coord. Santiago de Chile: Fondo de Cultura Económica, 2014: 363-392.

Farge, Arlette, La atracción del archivo. Valencia: Edicions Alfons El Magnánim, 1991.

Fernández Saldaña, J. M., Diccionario uruguayo de biografías, 1810-1940. Montevideo: Editorial Amerindia, 1945.

Ferreira, Pablo, "Ciudadanos en armas. La experiencia de la milicia cívica en Montevideo, 1815-1817», Claves. Revista de Historia. 2 (enero-junio 2016): 945 .

Fessler, Daniel, «Militares y «malhechores» entre la justicia militar y la justicia criminal», Passagens. Revista Internacional de História Política e Cultura Jurídica. 1 (ene-abr 2018): 4-23.

Fradkin, Raúl, «La revolución, los comandantes y el gobierno de los pueblos rurales. Buenos Aires, 1810-1822", Historia Crítica. 53 (may-agos 2014): 35- 59.

Fradkin, Raúl, «Guerra y sociedad en el litoral rioplatense en la primera mitad del siglo XIX», Las fuerzas de guerra en la construcción del Estado: América Latina, siglo XIX. Juan Garavaglia, Juan Pro, Eduardo Zimmermann eds. Rosario: Prohistoria ediciones, 2012: 319-356. 
Fradkin, Raúl, La historia de una montonera. Bandolerismo y caudillismo en Buenos Aires, 1826. Buenos Aires: Siglo Veintiuno Editores, 2006.

Fradkin, Raúl, «Bandolerismo y politización de la población rural de Buenos Aires tras la crisis de la independencia (1815-1830)», Nuevo mundo mundos nuevos. (2005). Disponible en https://journals.openedition.org/nuevomundo/309

Frega, Ana (coord.), Los orientales en armas. Estudios sobre la experiencia militar en la revolución artiguista. Montevideo: Universidad de la República-Ediciones Universitarias, 2014.

Frega, Ana, coord., Historia regional e independencia del Uruguay. Montevideo: Ediciones de la Banda Oriental, 2009.

Frega, Ana, «Después de la derrota. Apuntes sobre la recomposición de los liderazgos rurales en la campaña oriental a comienzos de la década de 1820». Desafíos al orden: política y sociedades rurales durante la Revolución de Independencia, Raúl Fradkin y Jorge Gelman comp. Rosario: Prohistoria, 2008: 131-152.

Frega, Ana, Pueblos y soberanía en la revolución artiguista. La región de Santo Domingo de Soriano desde fines de la colonia a la ocupación portuguesa. Montevideo: Ediciones de la Banda Oriental, 2007.

Frega, Ana, «Caudillos y montoneras en la revolución radical artiguista», Andes. 13 (2002): 75-112.

Garavaglia, Juan Carlos, San Antonio de Areco, 1680-188o: Un pueblo de la campaña, del Antiguo Régimen a la modernidad argentina. Rosario: Prohistoria, 2009.

Gelman, Jorge, "Crisis y reconstrucción del orden en la campaña de Buenos Aires. Estado y sociedad en la primera mitad del siglo XIX", Boletín del Instituto de Historia Argentina y Americana "Dr. Emilio Ravignani". 21 (1. ${ }^{\mathrm{er}}$ semestre 2000): 7-31.

Goldman, Noemí, «Legalidad y legitimidad en el caudillismo. Juan Facundo Quiroga y La Rioja en el interior rioplatense (1810-1835)», Boletín del Instituto de Historia Argentina y Americana "Dr. Emilio Ravignani". 7 (1er semestre 1993): 31-58.

Halperin Donghi, Tulio, Revolución y guerra. Formación de una elite dirigente en la Argentina criolla. Buenos Aires: Siglo Veintiuno Editores, 2005.

Kühn, Fabio, et al., «Trajetórias sociaas e prácticas políticas nas franjas do império», História, histórias. 1 (2013): 46-71.

Lynch, John, Caudillos en Hispanoamérica, 1800-1850. Madrid: Mapfre, 1993.

Magariños De Mello, Mateo, El Gobierno del Cerrito. Colección de documentos oficiales emanados de los poderes del gobierno presidido por el Brigadier General D. Manuel Oribe -1843-1851, Volumen 1. Montevideo: El Siglo Ilustrado, 1948.

Marchena Fernández, Juan, Ejército y milicias en el mundo colonial americano. Madrid, Mapfre, 1992.

Osório, Helen, O império português no sul da América: estancieiros, lavradores e comerciantes. Porto Alegre: Editora da UFRGS, 2007.

Pintos Diago, César, Leonardo Olivera: el señor del este. Montevideo: Claudio García, 1945 . 
Pivel Devoto, Juan E., Historia de los partidos políticos en el Uruguay, Tomo I. Montevideo: Claudio Garcia y Cia Editores, 1942.

Rabinovich, Alejandro, «La militarización del Río de la plata, 1810-1820. Elementos cuantitativos y conceptuales para un análisis», Boletín del Instituto de Historia Argentina y Americana «Dr. Emilio Ravignani». 37 (segundo semestre 2012): 11-42.

Seijo, Carlos, Carolinos ilustres, patriotas y beneméritos. Montevideo: Imprenta El Siglo Ilustrado, 1936.

Ternavasio, Marcela, La revolución del voto. Buenos Aires: Siglo Veintiuno Editores, 2001.

Vanderwood, Paul J., «Los bandidos de Manuel Payno», Historia Mexicana. I (1994): 107-139.

Vilar, Pierre, Iniciación al vocabulario del análisis histórico. Barcelona: Crítica, 1982. 